\title{
Socioeconomic Status And Acute Stroke Care: Has The Inequality Gap Been Closed?
}

This article was published in the following Dove Press journal:

Clinical Epidemiology

\author{
Vibe Bolvig Hyldgård (D) ${ }^{1,2}$ \\ Søren Paaske Johnsen (iD) ${ }^{3}$ \\ Henrik Støvring (iD) 4 \\ Rikke Søgaard (iD) ${ }^{1,5}$ \\ 'Department of Public Health, Aarhus \\ University, Aarhus C 8000, Denmark; \\ ${ }^{2}$ Health Economics, DEFACTUM, Central \\ Region Denmark, Aarhus N 8200, \\ Denmark; ${ }^{3}$ Danish Center for Clinical \\ Health Services Research, Department of \\ Clinical Medicine, Aalborg University \\ Hospital, Aalborg 9000, Denmark; \\ ${ }^{4}$ Department of Public Health - Biostatistics, \\ Aarhus University, Aarhus C 8000, \\ Denmark; ${ }^{5}$ Department of Clinical \\ Medicine, Aarhus University, Aarhus N \\ 8200, Denmark
}

\begin{abstract}
Purpose: Socioeconomic inequality in stroke care occurs even in countries with free access to health care. We aimed to investigate the association between socioeconomic status and guideline-recommended acute care in Denmark during the last decade.

Design: We conducted a nationwide, population-based study. We used household income, employment status, and education as markers of socioeconomic status and adjusted the results for relevant clinical covariates. We used weighted linear regression models to analyse empirical log odds of performance measure fulfillment at patient level.
\end{abstract}

Setting: Public hospitals in Denmark.

Participants: A total of 110,848 consecutive stroke patients discharged between 2004 and 2014. Intervention(s): Acute stroke care according to clinical guidelines.

Main outcome measure(s): Guideline-recommended care was defined in two ways based on clinical performance measures: the percentage of fulfilled measures used throughout the study period $(\mathrm{m}=8)$ (model 1$)$ and the percentage of fulfilled measures used at the time of discharge ( $m=8$ to 16$)$ (model 2 ).

Results: Compared with high family income, low income was negatively associated with the guideline-recommended care; odds ratios $(95 \% \mathrm{CI})$ were $0.89(0.85-0.93)$ in model 1 and $0.81(0.77-0.85)$ in model 2 . Low family income was negatively associated with fulfillment of 14 of the 16 performance measures. In general, the percentage of performance measures fulfilled increased over time from 70\% (95\% CI 63-76) to 85\% (95\% CI 83-87).

Conclusion: Socioeconomic inequality in guideline-recommended stroke care remains despite overall improvements in a setting with free access to care and systematic monitoring of health care quality.

Keywords: quality of care, access to care, health inequality, stroke

\section{Introduction}

Health care systems may contribute to health inequalities by providing variable access to care. ${ }^{1,2}$ There is evidence that even in societies with theoretically equal access to publicly financed health care, the utilization of health care services varies according to patient characteristics beyond clinical needs. ${ }^{3-7}$

The existence of socioeconomic inequality in the risk of stroke is well documented. ${ }^{8}$ Similar findings apply to the prognosis after a stroke in relation to recurrence, ${ }^{9}$ poststroke disability, ${ }^{10}$ and survival. ${ }^{8,11}$ Although few researchers have investigated inequality in the provision of stroke care, a social gradient has been identified in the likelihood of receiving evidence-based stroke care even in countries with free access to health care. ${ }^{8,12}$ Low income, lower educational level, and receipt of a disability pension have been found to be associated with a smaller
Correspondence: Vibe Bolvig Hyldgård Department of Public Health, Aarhus University, Aarhus C 8000, Denmark

Tel +453 II 91504

Fax +45784I4029

Email vibe.bolvig@rm.dk 
chance of receiving care in accordance with clinical guideline recommendations. ${ }^{13-18}$

In countries with universal health care systems, a common goal in health care policy is to treat all patients equally. ${ }^{19}$ Little has been published about the best ways to attain such equality. In an ongoing monitoring and auditing effort initiated in 2003, Danish hospitals aim to improve the process quality of acute stroke care and ensure an even distribution of high-quality care. ${ }^{20}$ However, changes in patterns of inequality over time have been left largely unaddressed in both the national and international literature on stroke and it is unknown whether quality of care initiatives lead to equally distributed improvements of care.

Changes in inequality of care over time are of key interest to policymakers when qualifying political initiatives. ${ }^{17}$ Such knowledge can also inform clinicians working to advance equality in care. The objective of this study was to investigate the association between socioeconomic status and guideline-recommended acute stroke care over time in Denmark.

\section{Methods}

\section{Study Design}

This register-based nationwide study was performed in a setting of publicly funded hospitals using patient-level data from the Danish Stroke Register (DSR). Reporting to the DSR is mandatory for all departments treating acute stroke patients. The DSR is a validated nationwide clinical quality database with an estimated sensitivity of $97 \%{ }^{21}$ The cohort of consecutive stroke patients discharged from January 1st, 2004 to December 31st, 2014 was identified in the DSR, and the data were linked to several national registers under Statistics Denmark using personal identification numbers. $^{22,23}$

Acute stroke care is provided only at public hospitals in Denmark. More than $90 \%$ of all acute stroke patients were treated at specialized multidisciplinary stroke units in the study period. Stroke care was substantially centralized during the study period with 52 units receiving patients in 2004 compared with 25 in 2014, including 8 centers providing i.v. thrombolysis and 3 comprehensive stroke centers providing both i.v. thrombolysis and thrombectomy. The stroke units were in the start of the study period organized within a mixture of departments of neurology and internal medicine, respectively, however, by the end of the study period, the units were all organized within departments of neurology.
Patients registered with an acute ischemic or haemorrhagic stroke were included, whereas patients with transient ischemic attack were excluded. We only included the first event for patients with multiple recorded events during the study period.

\section{Socioeconomic Status}

Variables defining the socioeconomic status of the patients were obtained from Statistics Denmark. ${ }^{24}$ From the year of discharge, disposable family income and the patients' highest achieved educational level were obtained. We classified family income as high, medium, or low according to tertiles within the study population and educational level as primary, upper secondary, or higher. Employment status was based on the first registration in the year before discharge and was categorized as working, retired (including early retirement and disability pension), or unemployed.

\section{Potential Confounders}

Potential confounding factors were considered. From the DSR, we retrieved information on the following patient characteristics: age, sex, Scandinavian Stroke Scale score at the time of admission, ${ }^{25}$ and a history of diabetes mellitus, hypertension, or stroke in the year of discharge. We also retrieved information on the treating hospital department from the DSR (each department is identified by an id, which marks both the department and the hospital it falls under).

\section{Quality Of Acute Stroke Care}

We defined guideline-recommended care using clinical performance measures obtained from the DSR. The Danish stroke guidelines are in accordance with the guidelines stated by the European Stroke Organisation and the American Heart Association. ${ }^{20}$ The performance measures reflect the provision of the core processes of early stroke care including diagnostics, treatment, and early rehabilitation in accordance with recommendations from the national clinical guidelines. ${ }^{26}$ Based on detailed written instructions, the hospital personnel classify every patient as eligible or not for each performance measure according to the presence of contraindications. ${ }^{15,20}$ For example, severe dementia in a patient with ischemic stroke and atrial fibrillation can preclude oral anticoagulant therapy and rapid spontaneous recovery of motor symptoms makes early assessment by physiotherapist and occupational therapist irrelevant. $^{15}$ The medical relevance of each 
performance measure is therefore incorporated into the registration and consequently included in this study.

During the study period, the number of performance measures increased from 8 to 16 (See Table 1). The definition of the original 8 measures was unchanged. We constructed 2 models. In model 1, the guideline-recommended care was based on the 8 measurers used throughout the period. This allowed consistent comparisons over time. In model 2, guideline-recommended care was based on the 8 to 16 measures that were available at the time of discharge, which provided an outcome that directly reflected what was considered guideline-recommended care at that time. For an overview of the included performance measures and the periods in which they were available, see Table 1.

\section{Statistical Analysis}

The study population was characterized using frequencies and means with standard errors. As we wanted to compare process performance fulfillment between patients we constructed an aggregated outcome for each patient by computation of the empirical odds of fulfillment for each patient. With a continuity correction, it has previously been shown that such empirical odds may be analyzed validly after a log-transformation using ordinary linear regression with analytical weights. ${ }^{27,28}$ Specifically, we used an empirical logistic transformation of the outcomes as follows:

$$
Z=\log \left(\frac{y+\frac{1}{2}}{m-y+\frac{1}{2}}\right)
$$

where $\mathrm{Z}$ is the model outcome, $\mathrm{y}$ represents the number of performance measures fulfilled and $\mathrm{m}$ the relevant performance measures. Gart and Zweifel studied the bias of logit estimators and their variance estimators and identified a variance estimator that yielded results with very little bias. McCullagh and Nelder applied the variance estimator derived by Gart as an analytical weight as they found that it diminishes the issue of the variance not being homogeneous and thus allows valid inference of empirical logits by use of linear regression. Their analytical weight w was therefore applied: ${ }^{29,30}$

$$
w=\left(y+\frac{1}{2}\right)^{-1}+\left(m-y+\frac{1}{2}\right)^{-1}
$$

As a consequence of the transformation we used, the interpretation of the coefficients of the regression analysis follows that of a logistic regression; i.e., the exponential of the coefficient represents the odds ratio associated with a 1-unit change in the covariate. Multilevel modeling was used as the patient level was nested within the hospital

\begin{tabular}{|c|c|}
\hline Performance Measure & $\begin{array}{l}\text { Period } \\
\text { Available }\end{array}$ \\
\hline Ischemic stroke patient without atrial fibrillation receives platelet-inhibitor therapy within 2 days of admission & $2004-2014$ \\
\hline Ischemic stroke patient with atrial fibrillation receives oral anticoagulation therapy within 14 days after admission & $2004-2014$ \\
\hline Stroke patient is examined with a CT/MRI scan on the day of admission & $2004-2014$ \\
\hline $\begin{array}{l}\text { Stroke patient is assessed by a physiotherapist about the need for rehabilitation (including type and extent) within the second } \\
\text { day of admission }\end{array}$ & $2004-2014$ \\
\hline $\begin{array}{l}\text { Stroke patient is assessed by an occupational therapist about the need for rehabilitation (including type and extent) within the } \\
\text { second day of admission }\end{array}$ & $2004-2014$ \\
\hline Stroke patient is mobilized on the day of admission & 2004-2014 \\
\hline Stroke patient receives a nutritional risk assessment within the second day of admission & 2004-2014 \\
\hline Stroke patient is admitted to a stroke unit within the second day of admission & $2004-2014$ \\
\hline Ischemic stroke patient is examined with ultrasound or CT/MR angiography of the carotid arteries within 4 days of admission & $2007-2014$ \\
\hline Stroke patient is admitted to a hospital within $3 \mathrm{hrs}$ after symptom onset & $2009-2014$ \\
\hline Stroke patient is admitted to a hospital within $4.5 \mathrm{hrs}$ of symptom onset & $2009-2014$ \\
\hline $\begin{array}{l}\text { Stroke patient receives indirect swallowing test on the day of admission before receiving food or fluids to assess swallowing } \\
\text { function and risk of aspiration }\end{array}$ & $2011-2014$ \\
\hline $\begin{array}{l}\text { Stroke patient receives direct swallowing test on the day of admission before receiving food or fluids to assess swallowing } \\
\text { function and risk of aspiration }\end{array}$ & $2011-2014$ \\
\hline Ischemic stroke patient undergoes carotid endarterectomy within 14 days of admission & $2011-2014$ \\
\hline Stroke patient is treated with thrombolysis and has a door-to-needle time of $\leq \mathrm{l} \mathrm{hr}$ & $2011-2014$ \\
\hline Ischemic stroke patient receives thrombolysis & $2011-2014$ \\
\hline
\end{tabular}

Table I Individual Performance Measures Of Guideline-Recommended Care Over Time 
department level. The assumptions for linear regression and alternative functional scaling of variables were tested. To illustrate the development graphically over time, regression models for each year allowed for effect modification between year and the other covariates. Ordinary logistic regression was used to investigate the associations between each of three socioeconomic characteristics and the individual performance measures. The linear regression analyses were also performed for specified periods related to the time of introduction of new performance measures to identify changes over time in socioeconomic inequality in the percentage of guideline-recommended care fulfilled and tested for interaction between time and socioeconomic status. We performed several sensitivity analyses. For handling of missing observations on educational level, family income and employment status we replaced the missing observations with the levels associated with the worst/best outcome, respectively. To test an alternative operationalisation of guideline-recommended care we defined a dichotomous all-or-none outcome (whether each patient received all the relevant measures or not). As an alternative to applying the empirical logistic approach, we tested a logistic regression model with random effects using each indicator as the unit of the analysis. Finally, we performed several analyses where the study population was defined in different ways to locate the effect of patient homogeneity: inclusion of only first ever strokes, restriction to patients with more than three relevant performance measures and a stratified analysis according to the type of stroke.

All estimates were reported with $95 \%$ confidence intervals $(\mathrm{CI})$ and tests were 2 -sided with a $5 \%$ significance level. Stata SE 14.2 (StataCorp) was used for the statistical analyses.

\section{Ethics}

This study was conducted in agreement with the Act on the Processing of Personal Data (Danish Data Protection Agency journal number 2015-57-0002). Approval from the ethics committee is not required for register-based studies according to Danish law.

\section{Results}

A total of 110,848 individual stroke patients were included in the study. The regression analyses were based on 74,468 individual patients due to missing data in one or more of the socioeconomic and prognostic characteristics in the model. Descriptive characteristics of the study population and the distribution of missing data are shown in Table 2. We identified some differences between the patients included in the models and the patients with incomplete data. It is likely that these differences are related to the fact that patients in the oldest age group are highly overrepresented among patients with incomplete data $(34.5 \%$ vs $8.7 \%$ ). This would explain why patients with incomplete data have a smaller family income and are more likely to be retired (cf. Table 2). Due to the large sample size, all differences between patients with complete data and patients with incomplete data were statistically significant.

Being in the low or middle tertile of family income or being retired was negatively associated with guidelinerecommended care compared with being in the high family income tertile or having a job, respectively (Table 3). These associations were most pronounced in the model based on all available performance measures at the time of discharge (model 2).

Timely carotid endarterectomy and door-to-needle time for thrombolysis were the only two performance measures not significantly associated with family income. For employment status, indications of inequality were found for nine performance measures, including platelet-inhibitor therapy, CT/MR scan, early mobilization, nutritional risk assessment, angiography, early admission (within 3 and $4.5 \mathrm{hrs}$, respectively), swallowing test (indirect and direct), timely carotid endarterectomy, door-to-needle time for thrombolysis and use of thrombolysis. In contrast, only two performance measures were associated with educational level, i.e., angiography and indirect swallowing test. Please see supplementary tables S1-S16 for complete results for the individual performance measures.

The changes over time are illustrated in Figure 1 as the overall percentages of guideline-recommended care fulfilled. When the model was based on the measures consistent over time (model 1) the fulfillment increased significantly from $69.9 \%$ (95\% CI 63.0-75.9) in 2004 to $85.0 \%$ (95\% CI 83.0-86.8) in 2014 when all covariates are at reference level. When the model was based on all atthe-time available measures (model 2), the percentage increased to $86.6 \%$ (95\% CI 83.4-89.2) (see Figure 1). (See supplementary figure S1 for the development over time in the crude average performance).

When restricting the analyses to performance measures that were consistent throughout the period studied, we found some indication that the inequality in relation to income and employment status may have been decreasing over time (Table 4); however, test for interaction revealed that this 
Table 2 Characterization Of The Study Population (n (\%))

\begin{tabular}{|c|c|c|c|}
\hline & $\begin{array}{l}\text { Patients With Complete Data } \\
(\mathrm{N}=\mathbf{7 4 , 4 6 8 )}\end{array}$ & $\begin{array}{l}\text { Patients With Incomplete Data } \\
(\mathrm{N}=\mathbf{3 6 , 3 8 0})\end{array}$ & $\begin{array}{l}\text { All Patients } \\
(\mathrm{N}=|1| 0,848)\end{array}$ \\
\hline \multicolumn{4}{|l|}{ Family income (price year 2015) } \\
\hline $25 \%$ percentile (\$22 915) & $21,337(28.7)$ & $12,189(33.5)$ & $33,526(30.2)$ \\
\hline $50 \%$ percentile $(\$ 3|| 4 \mid)$ & $25,434(34.2)$ & $8154(22.4)$ & $33,588(30.3)$ \\
\hline 75\% percentile ( $\$ 46787$ ) & $27,697(37.2)$ & $5911(16.2)$ & $33,608(30.3)$ \\
\hline Missing observations & $0(0.0)$ & $10,126(27.8)$ & $10,126(9.1)$ \\
\hline \multicolumn{4}{|l|}{ Employment status } \\
\hline Working & $16,504(22.2)$ & $3,915(10.8)$ & $20,419(18.4)$ \\
\hline Retired & $55,624(74.7)$ & $30,542(84.0)$ & $86,166(77.7)$ \\
\hline Unemployed & $2,340(3.1)$ & $800(2.2)$ & $3,140(2.8)$ \\
\hline Missing observations & $0(0.0)$ & $\mathrm{I}, 123(3.1)$ & $1,123(1.0)$ \\
\hline \multicolumn{4}{|l|}{ Highest achieved educational level } \\
\hline Primary & $35,994(48.3)$ & II,257 (30.9) & $47,25 I(42.6)$ \\
\hline Upper secondary & $27,391(36.8)$ & $8,325(22.9)$ & $35,716(32.2)$ \\
\hline Higher & II,083 (14.9) & $3,462(9.5)$ & $14,545(13.1)$ \\
\hline Missing observations & $0(0.0)$ & $13,336(36.7)$ & $13,336(12.0)$ \\
\hline \multicolumn{4}{|l|}{ Age group, years } \\
\hline$<65$ & $24,534(32.9)$ & $7,345(20.2)$ & $31,879(28.8)$ \\
\hline $65-74$ & $21,112(28.4)$ & $6,75 I(18.6)$ & $27,863(25.1)$ \\
\hline $75-84$ & $22,334(30.0)$ & $9,719(26.7)$ & $32,053(28.9)$ \\
\hline$>85$ & $6,488(8.7)$ & $12,565(34.5)$ & $19,053(17.2)$ \\
\hline Missing observations & $0(0.0)$ & $0(0.0)$ & $0(0.0)$ \\
\hline \multicolumn{4}{|l|}{ Sex } \\
\hline Female & $33,817(45.4)$ & $|8,76|(5 \mid .6)$ & $52,578(47.4)$ \\
\hline Male & $40,651(54.6)$ & $17,619(48.4)$ & $58,270(52.6)$ \\
\hline Missing observations & $0(0.0)$ & $0(0.0)$ & $0(0.0)$ \\
\hline \multicolumn{4}{|l|}{ Previous stroke } \\
\hline No & $61,564(82.7)$ & $24,379(67.0)$ & $85,943(77.5)$ \\
\hline Yes & $12,904(17.3)$ & $7,047(19.4)$ & $|9,95|(18.0)$ \\
\hline Missing observations & $0(0.0)$ & $4,954(13.6)$ & $4,954(4.5)$ \\
\hline \multicolumn{4}{|l|}{ Diabetes mellitus } \\
\hline No & $64,182(86.2)$ & $27,320(75.1)$ & $91,502(82.5)$ \\
\hline Yes & $10,286(13.8)$ & $4,843(13.3)$ & $15,129(13.6)$ \\
\hline Missing observations & $0(0.0)$ & $4,217(I 1.6)$ & $4,217(3.8)$ \\
\hline \multicolumn{4}{|l|}{ Hypertension } \\
\hline No & $34,805(46.7)$ & $14,332(39.4)$ & $49,137(44.3)$ \\
\hline Yes & $39,663(53.3)$ & I6,257 (44.7) & $55,920(50.4)$ \\
\hline Missing observations & $0(0.0)$ & $5,791(15.9)$ & $5,79 \mid(5.2)$ \\
\hline \multicolumn{4}{|l|}{ Scandinavian Stroke Scale score } \\
\hline I. Very severe (0-14 points) & $4,862(6.5)$ & $5,265(14.5)$ & $10,127(9.1)$ \\
\hline 2. Severe (15-29 points) & $6,179(8.3)$ & $3,81 I(10.5)$ & $9,990(9.0)$ \\
\hline 3. Moderate (30-44 points) & $12,975(17.4)$ & $5,396(14.8)$ & $|8,37|(16.6)$ \\
\hline 4. Mild (45-58 points) & $50,452(67.7)$ & $9,746(26.8)$ & $60,198(54.3)$ \\
\hline Missing observations & $0(0.0)$ & $12,162(33.4)$ & $12,162(11.0)$ \\
\hline
\end{tabular}

trend was not statistically significant. Basing guideline-recommended care on all performance measures available at the time of discharge showed a nonsignificant increase in the income- related inequality (Table 5). Over the studied period there is a shift in the distribution of income and, to less extent, education (see Figure 1). (See supplementary figures S2-4). The 
Table 3 Association Between Socioeconomic Status And Guideline-Recommended Care. OR (95\% Cl) P-Value*

\begin{tabular}{|c|c|c|c|c|}
\hline \multirow[b]{2}{*}{ Family income tertile } & \multicolumn{2}{|c|}{$\begin{array}{l}\text { Based On } 8 \text { Measures Consistent Over } \\
\text { Time }\end{array}$} & \multicolumn{2}{|c|}{$\begin{array}{l}\text { Based On } \geq 16 \text { Measure Available At The Time Of } \\
\text { Discharge }\end{array}$} \\
\hline & & & & \\
\hline Low & $0.89(0.85-0.93)$ & $<0.001$ & $0.81(0.77-0.85)$ & $<0.001$ \\
\hline Middle & $0.96(0.93-0.98)$ & 0.002 & $0.90(0.87-0.94)$ & $<0.001$ \\
\hline High & I (Ref.) & & I (Ref.) & \\
\hline \multicolumn{5}{|l|}{ Employment status } \\
\hline Working & I (Ref.) & & I (Ref.) & \\
\hline Retired & $0.96(0.93-0.99)$ & 0.025 & $0.91(0.87-0.96)$ & $<0.001$ \\
\hline Unemployed & $0.98(0.93-1.04)$ & 0.49 & $1.02(0.94-1.10)$ & 0.62 \\
\hline \multicolumn{5}{|l|}{ Highest achieved educational level } \\
\hline Primary & $1.00(0.96-1.04)$ & 0.97 & $0.96(0.91-1.02)$ & 0.18 \\
\hline Upper secondary & I.0I (0.98-I.04) & 0.35 & $0.99(0.95-1.03)$ & 0.69 \\
\hline Higher & I (Ref.) & & I (Ref.) & \\
\hline Reference person** & $1.50(1.18-1.91)$ & 0.001 & $2.03(1.59-2.58)$ & $<0.001$ \\
\hline $\mathrm{R}^{2}$ & 0.163 & & 0.072 & \\
\hline $\mathrm{n}$ & 74,468 & & 74,468 & \\
\hline
\end{tabular}

Notes: *Odds Ratios $(95 \% \mathrm{Cl})$ of the percentage of guideline-recommended care fulfilled adjusted for sex, age, previous stroke, diabetes mellitus, hypertension, stroke severity, and year. Multilevel modeling was used. **Odds for a patient at reference level (high income, employed, higher education).

inequality in income increased over time while it slightly decreased in education.

All the performed sensitivity analyses supported the main analyses (data not shown).

\section{Discussion}

This study demonstrates that there is socioeconomic inequality in acute stroke care as high-income patients receive better care within the publicly funded health care system of Denmark. After a decade with mandatory monitoring and auditing of clinical performance, the fulfillment

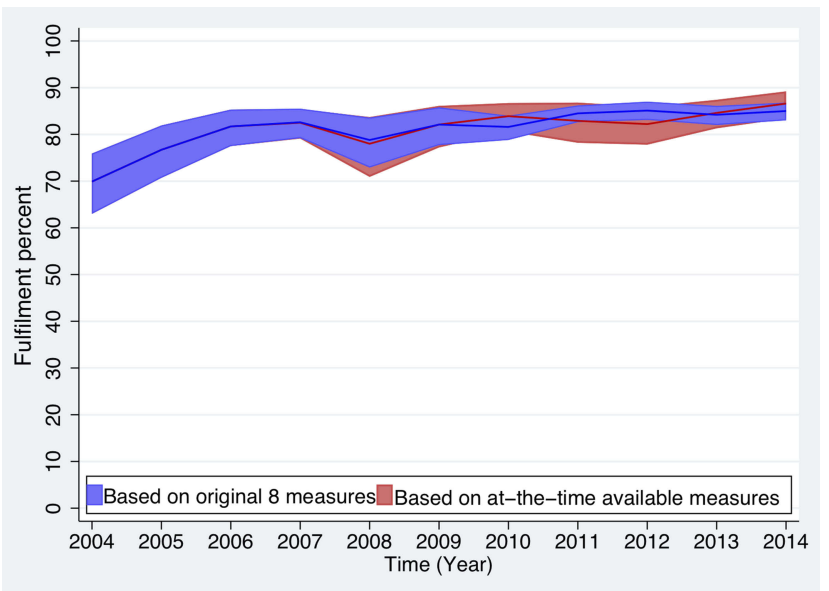

Figure I Percentages of guideline-recommended care fulfilled $(95 \% \mathrm{Cl})$. Abbreviations: $\mathrm{Cl}$, confidence interval; DSR, Danish Stroke Register; OR, odds ratio. of guideline-recommended care has improved substantially, but this has not translated to reduced socioeconomic inequality.

\section{Comparison With Other Studies}

Data on time trends in inequality of stroke care are sparse. An exemption is an English study of 4202 stroke patients from Southern London that reported a decrease in socioeconomic inequality in the provision of care between 1995 and 2010, however, the authors concluded that further efforts were required to achieve equality in stroke care. ${ }^{17}$ The existence of social inequality was confirmed in a recent national study from England as patients were less likely to receive 5 out of 12 care processes if they had a low socioeconomic status. ${ }^{31}$ The inequality identified in our study is slightly more pronounced, which may relate to the fact that the English studies used an area-based measure of social deprivation while we applied individual-level data. In a Danish context, our findings are consistent with a study covering the period 2003-2007 showing that low personal income and disability pension were associated with a lower probability of receiving the recommended care. ${ }^{16}$ An Austrian study found educational level to be associated with stroke care, but this incongruence might be related to the use of educational level as their sole measure of socioeconomic status. ${ }^{18}$ With the inclusion of three socioeconomic characteristics, it is natural to see smaller associations compared to studies that include 
Table 4 Association Between Socioeconomic Status And Guideline-Recommended Care For Separate Time Periods Based On 8 Measures Consistent Over Time. OR (95\% Cl) P-Value*

\begin{tabular}{|c|c|c|c|c|c|c|c|c|}
\hline \multirow[b]{2}{*}{ Family income tertile } & \multicolumn{2}{|l|}{ 2004-2006 } & \multicolumn{2}{|l|}{ 2007-2008 } & \multicolumn{2}{|l|}{$2009-2010$} & \multicolumn{2}{|l|}{$2011-2014$} \\
\hline & & & & & & & & \\
\hline Low & $0.84(0.76-0.93)$ & 0.002 & $0.88(0.80-0.97)$ & 0.008 & $0.85(0.79-0.91)$ & $<0.001$ & $0.93(0.89-0.98)$ & 0.004 \\
\hline Middle & $0.93(0.84-1.03)$ & 0.18 & $0.95(0.89-1.03)$ & 0.20 & $0.94(0.90-0.99)$ & 0.015 & $0.97(0.95-1.00)$ & 0.033 \\
\hline High & I (Ref.) & & I (Ref.) & & I (Ref.) & & I (Ref.) & \\
\hline \multicolumn{9}{|l|}{ Employment status } \\
\hline Working & I (Ref.) & & I (Ref.) & & I (Ref.) & & I (Ref.) & \\
\hline Retired & $0.88(0.78-1.00)$ & 0.045 & $0.98(0.92-1.05)$ & 0.61 & $0.96(0.90-1.02)$ & 0.20 & $0.98(0.95-1.02)$ & 0.33 \\
\hline Unemployed & $0.99(0.87-1.13)$ & 0.92 & $1.07(0.89-1.29)$ & 0.47 & $1.01(0.88-1.16)$ & 0.87 & $0.93(0.88-0.99)$ & 0.018 \\
\hline \multicolumn{9}{|l|}{ Highest achieved educational level } \\
\hline Primary & $0.93(0.83-1.05)$ & 0.24 & $1.05(0.96-1.15)$ & 0.29 & $1.04(0.97-1.11)$ & 0.31 & $1.00(0.96-1.03)$ & 0.76 \\
\hline Upper secondary & $0.95(0.86-1.05)$ & 0.29 & $1.03(0.97-1.09)$ & 0.31 & $1.06(1.00-1.13)$ & 0.049 & $1.01(0.99-1.04)$ & 0.28 \\
\hline Higher & I (Ref.) & & I (Ref.) & & I (Ref.) & & I (Ref.) & \\
\hline Reference person** & $2.29(1.80-2.92)$ & $<0.001$ & $4.03(3.23-5.04)$ & $<0.001$ & $4.00(3.25-4.91)$ & $<0.001$ & $5.16(4.57-5.84)$ & $<0.001$ \\
\hline$R^{2}$ & 0.059 & & 0.013 & & 0.027 & & 0.040 & \\
\hline $\mathrm{n}$ & 18,346 & & 12,565 & & 13,690 & & 29,867 & \\
\hline
\end{tabular}

Notes: *Odds Ratios $(95 \% \mathrm{Cl})$ of the percentage of guideline-recommended care fulfilled adjusted for sex, age, previous stroke, diabetes mellitus, hypertension, stroke severity, and year. Multilevel modeling was used. **Odds for a patient at reference level (high income, employed, higher education).

Table 5 Association Between Socioeconomic Status And Guideline-Recommended Care For Separate Time Periods Based On Up To 16 Measures Available At The Time Of Discharge. OR (95\% Cl) P-Value*

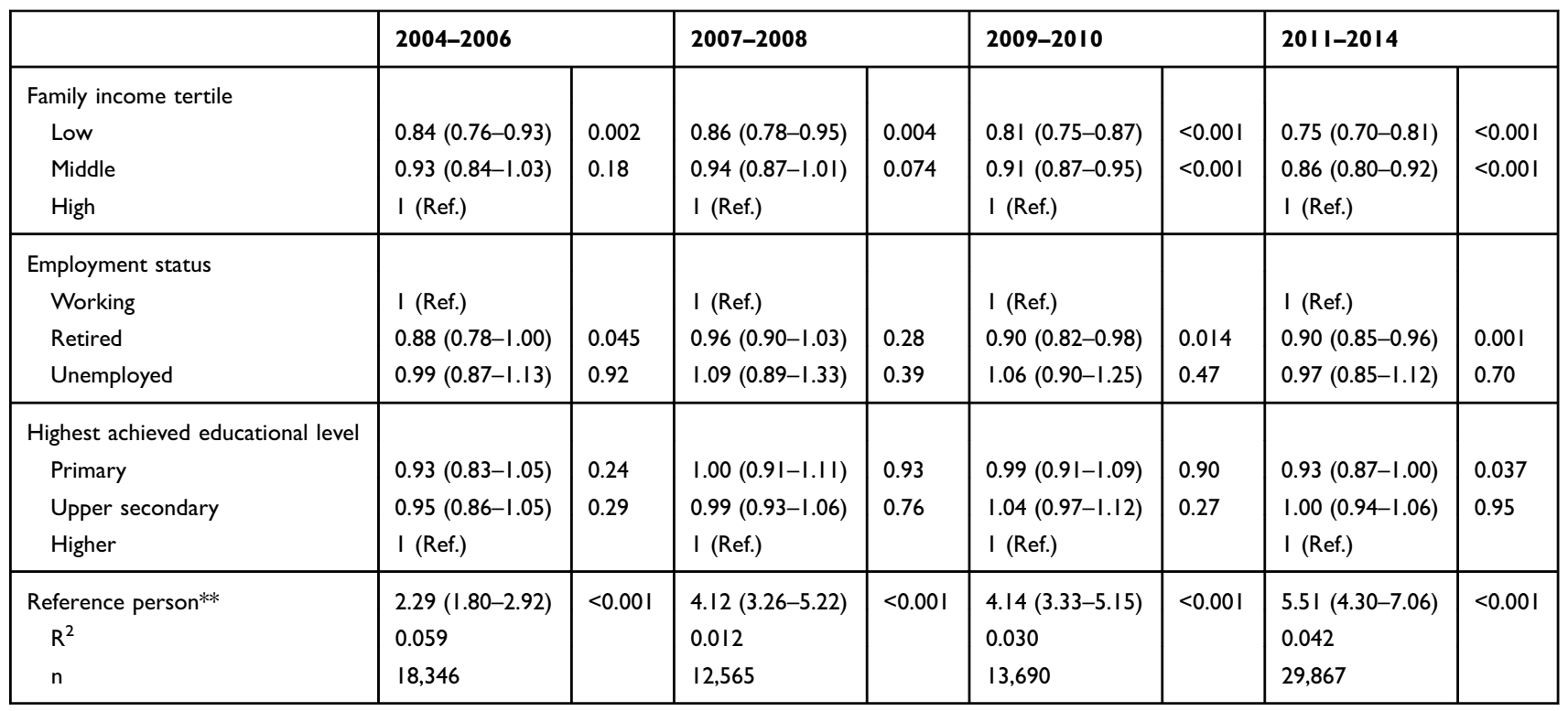

Notes: *Odds Ratios $(95 \% \mathrm{Cl})$ of the percentage of guideline-recommended care fulfilled adjusted for sex, age, previous stroke, diabetes mellitus, hypertension, stroke severity, and year. Multilevel modeling was used. **Odds for a patient at reference level (high income, employed, higher education).

only one characteristic. In addition, patients' education and employment status have previously been found to be less determined than their income in old age. ${ }^{32}$ The finding that family income was more closely associated with receiving the recommended care could also be related to the fact that it includes information regarding the patients' partners.

\section{Main Strengths And Weaknesses Of The Study}

The data applied in this study represent a key strength. The data had been validated, and the DSR has been found to have a high sensitivity. ${ }^{21}$ In addition, the registers have national coverage and the data were collected prospectively and on an 
individual level. The definition of guideline-recommended care was based on up to 16 performance measures of process quality, which is adopted by clinicians in general and is in consensus with international standards. A particular strength is that each measure comes with a registration of medical relevance for the individual patient. This makes for a more nuanced measure than a yes/no response to whether a given performance measure had been fulfilled. It also assists in removing potential heterogeneity in individual patient needs from the analysis. However, we cannot entirely exclude that misclassification may have occurred in the registration of medical relevance.

A weakness of this study is the degree of missing data on covariates as $33 \%$ of the patients had one or more missing observations. However, we have no reason to believe this affected the internal validity of the study. The missing values were not a result of nonresponse by patients and comparison of complete and incomplete cases revealed no systematic patterns in the association between guideline-recommended care and socioeconomic status. In addition, the robustness of the results was tested with several sensitivity analyses including worst-case and best-case scenario analyses, different definitions of outcome, different definitions of inclusion criteria, etc., neither of which substantially altered the results substantially. For further comparison of patients according to missing data see Table 2.

Working with the defined outcome allowed us to perform a nuanced analysis, but it may also represent a limitation because each performance measure was assigned equal weight and was therefore considered equally important components of care. Supplementary tables S1-16 accommodate such concern and offer an insight into the individual performance measures.

From a policy perspective, a limitation of this study is that it relied solely on measures of process quality in the medical technical sense, which may ignore other quality aspects of value-based health care.

\section{Perspectives/Implications}

Socioeconomic inequality seems to persist in acute stroke care even after a decade of systematic monitoring of clinical performance. The observed trend of increasing inequality in relation to the more recent measures of guideline-recommended care warrants specific consideration. The policy implication of these findings might be that even in a setting of proclaimed equal access to health care, additional effort is required to decrease socioeconomic inequality, especially when guideline-recommended care becomes further sophisticated through the addition of new components.

\section{Disclosure}

None of the authors have any conflicts of interest to declare in this work.

\section{References}

1. Lutfey KE, Campbell SM, Renfrew MR, Marceau LD, Roland M, McKinlay JB. How are patient characteristics relevant for physicians' clinical decision making in diabetes? An analysis of qualitative results from a cross-national factorial experiment. Soc Sci Med. 2008;67:1391-1399. doi:10.1016/j.socscimed.2008.07.005

2. Commission on Social Determinants of Health (CSDH). Closing the gap in a generation: health equity through action on the social determinants of health. Final Report of the Commission on Social Determinants of Health. Geneva: World Health Organization; 2008.

3. Siciliani L, Verzulli R. Waiting times and socioeconomic status among elderly Europeans: evidence from SHARE. Health Econ. 2009;18:1295-1306. doi:10.1002/hec.1429

4. Kjellén M, von Euler-Chelpin M. Socioeconomic status as determinant for participation in mammography screening: assessing the difference between using women's own versus their partner's. Int $J$ Public Health. 2010;55:209-215. doi:10.1007/s00038-010-0137-4

5. Libungan B, Karlsson T, Hirlekar G, Albertsson P, Herlitz J, RavnFischer A. Delay and inequality in treatment of the elderly with suspected acute coronary syndrome. Int J Cardiol. 2014;176:946950. doi:10.1016/j.ijcard.2014.08.109

6. Kærgaard Starr L, Osler M, Steding-Jessen M, et al. Socioeconomic position and surgery for early-stage non-small-cell lung cancer: a population-based study in Denmark. Lung Cancer. 2013;79:262269. doi:10.1016/j.lungcan.2012.11.023

7. Carlsen F, Kaarboe OM. The relationship between educational attainment and waiting time among the elderly in Norway. Health Policy. 2015;119:1450-1458. doi:10.1016/j.healthpol.2015.09.013

8. Addo J, Ayerbe L, Mohan KM, et al. Socioeconomic status and stroke: an updated review. Stroke. 2012;43:1186-1191. doi:10.1161/ STROKEAHA.111.639732

9. Pennlert J, Asplund K, Glader E, Norrving B, Eriksson M. Socioeconomic status and the risk of stroke recurrence: persisting gaps observed in a nationwide Swedish study 2001 to 2012. Stroke. 2017;48:1518-1523. doi:10.1161/STROKEAHA.116.015643

10. Bettger JP, Zhao X, Bushnell C, et al. The association between socioeconomic status and disability after stroke: findings from the Adherence eValuation After Ischemic stroke Longitudinal (AVAIL) registry. BMC Public Health. 2014;14:281. doi:10.1186/1471-2458-14-281

11. Chen R, McKevitt C, Rudd AG, Wolfe CD. Socioeconomic deprivation and survival after stroke. Findings from the prospective South London Stroke Register of 1995 to 2011. Stroke. 2014;45:217-224. doi:10.1161/STROKEAHA.113.003266

12. Pan Y, Chen R, Li Z, et al. Socioeconomic status and the quality of acute stroke care: the China National Stroke Registry. Stroke. 2016;47:2836-2842. doi:10.1161/STROKEAHA.116.013292

13. Kimball MM, Neal D, Waters MF, Hoh BL. Race and income disparity in ischemic stroke care: nationwide inpatient sample database, 2002 to 2008. J Stroke Cerebrovasc Dis. 2014;23:17-24. doi:10.1016/j.jstrokecerebrovasdis.2012.06.004

14. Palnum KD, Petersen P, Sørensen HT, et al. Older patients with acute stroke in Denmark: quality of care and short-term mortality. A nationwide follow-up study. Age Ageing. 2008;37:90-95. doi:10.1093/ageing/afm134 
15. Palnum KD, Andersen G, Ingeman A, Krog BR, Bartels P, Johnsen SP. Sex-related differences in quality of care and short-term mortality among patients with acute stroke in Denmark: a nationwide follow-up study. Stroke. 2009;40:1134-1139. doi:10.1161/STROKEAHA.108.543819

16. Langagergaard V, Palnum KH, Mehnert F, et al. Socioeconomic differences in quality of care and clinical outcome after stroke: a nationwide population-based study. Stroke. 2011;42:2896-2902. doi:10.1161/STROKEAHA.110.611871

17. Chen R, McKevitt C, Crichton SL, Rudd AG, Wolfe CD. Socioeconomic deprivation and provision of acute and long-term care after stroke: the South London Stroke Register cohort study. J Neurol Neurosurg Psychiatry. 2014;85:1294-1300. doi:10.1136/jnnp-2013-306413

18. Arrich J, Müllner M, Lalouschek W, Greisenegger S, Crevenna R, Herkner H. Influence of socioeconomic status and gender on stroke treatment and diagnostics. Stroke. 2008;39:2066-2072. doi:10.1161/ STROKEAHA.107.506147

19. The Ministry of the Interior and Health, Parliament, Margrethe II of Denmark. Health Act. §2 Denmark. 2005.

20. Johnsen SP, Ingeman A, Hundborg HH, Schaarup SZ, Gyllenborg J. The Danish Stroke Registry. Clin Epidemiol. 2016;8:697-702. doi:10.2147/CLEP.S103662

21. Wildenschild C, Mehnert F, Thomsen RW, et al. Registration of acute stroke: validity in the Danish Stroke Registry and the Danish National Registry of Patients. Clin Epidemiol. 2013;6:27-36. doi:10.2147/CLEP.S50449

22. Petersson F, Baadsgaard M, Thygesen LC. Danish registers on personal labour market affiliation. Scand J Public Health. 2011;39:9598. doi:10.1177/1403494811408483

23. Lynge E, Sandegaard JL, Rebolj M. The Danish National Patient Register. Scand J Public Health. 2011;39:30-33. doi:10.1177/ 1403494811401482

24. Thygesen LC, Daasnes C, Thaulow I, Brønnum-Hansen H. Introduction to Danish (nationwide) registers on health and social issues: structure, access, legislation, and archiving. Scand J Public Health. 2011;39:12-16. doi:10.1177/1403494811399956

25. Lindenstrøm E, Boysen G, Waage Christiansen L, À Rogvi Hansen B, Würtzen Nielsen P. Reliability of Scandinavian Neurological Stroke Scale. Cerebrovasc Dis. 1991;1:103-107. doi:10.1159/ 000108825

26. Competence Center for Clinical Epidemiology and Biostatistics, North (KCEB-North). Danish Stroke Register Annual Report 2013 Final Edition. 2014.

27. McCullagh P, Nelder J. Generalized Linear Models. 2nd ed. London: Chapman \& Hall; 1989.

28. Stevens S, Valderas JM, Doran T, Perera R, Kontopantelis E. Analysing indicators of performance, satisfaction, or safety using empirical logit transformation. BMJ. 2016;352:11114. doi:10.1136/ bmj.i1114

29. Gart JJ, Zweifel JR. On the bias of various estimators of the logit and its variance with application to quantal bioassay. Biometrika. 1967;54:181-187.

30. Donnelly S, Verkuilen J. Empirical logit analysis is not logistic regression Empirical logit analysis is not logistic regression. $\mathrm{J} \mathrm{Mem}$ Lang Elsevier Inc. 2017;94:28-42. doi:10.1016/j.jml.2016.10.005

31. Bray BD, Paley L, Hoffman A, et al. Socioeconomic disparities in first stroke incidence, quality of care, and survival : a nationwide registry-based cohort study of 44 million adults in England. Lancet Public Health. 2018;3:e185-93. doi:10.1016/S2468-2667(18) 30030-6

32. Darin-Mattsson A, Fors S, Kåreholt I. Different indicators of socioeconomic status and their relative importance as determinants of health in old age. Int J Equity Health. 2017;16:1-11.
Clinical Epidemiology

\section{Publish your work in this journal}

Clinical Epidemiology is an international, peer-reviewed, open access, online journal focusing on disease and drug epidemiology, identification of risk factors and screening procedures to develop optimal preventative initiatives and programs. Specific topics include: diagnosis, prognosis, treatment, screening, prevention, risk factor modification, systematic reviews, risk \& safety of medical interventions, epidemiology \& biostatistical methods, and evaluation of guidelines, translational medicine, health policies \& economic evaluations. The manuscrip management system is completely online and includes a very quick and fair peer-review system, which is all easy to use. 